
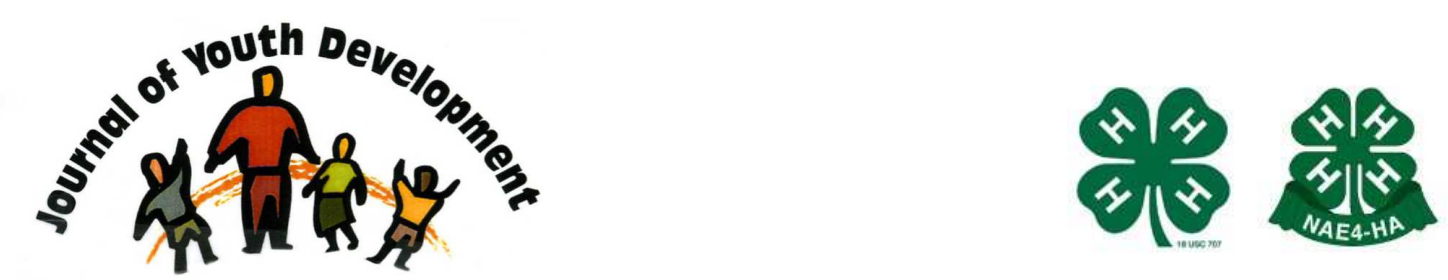

Bridging Research \& Practice

\title{
Excel Initiative: Excellence in Youth Programming
}

\author{
Lynne M. Borden \\ Department of Family Social Science \\ University of Minnesota \\ St. Paul, MN 55108 \\ Imborden@umn.edu \\ Kyle R. Hawley \\ University of Minnesota \\ C. Eddy Mentzer \\ Departments of Defense's Office of Family Readiness Policy
}




\title{
JOURNAL OF YOUTH DEVELOPMENT \\ bridging research and practice

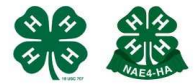

Volume 10, Number 2, Summer 2015

Article 151002PA002

\section{Excel Initiative: Excellence in Youth Programming}

\author{
Lynne M. Borden and Kyle R. Hawkey \\ University of Minnesota \\ C. Eddy Mentzer \\ Departments of Defense's Office of Family Readiness Policy
}

\begin{abstract}
The Excellence in Youth Programming (Excel) Initiative strives to support youth programs in delivering high quality programs. The backbone of Excel is the Youth Development Observational Tool (YDOT) which allows for the virtual assessment of program staff who work with children and youth ages 9-18 years. The YDOT also allows Excel to provide structured feedback to programs. Excel has several unique features, including a virtual platform and a focus on the relationships between adults and youth participating in after-school programs. Offering structured assessment and interaction online eliminates expenses, provides convenient access for programs around the globe, and allows for unobtrusive assessment of worker-youth interactions. Excel is also integrated into a broader network of resources, tools, and research for those working with children and youth ages 9-18.
\end{abstract}

\section{Introduction}

Fostering positive youth development requires intentional, planned scaffolding throughout childhood and adolescence. Empowering young people to be productive, engaged members of their community, and to develop healthy relationships necessitates broad-based efforts by all levels of the child's support system and broader community (Gambone, \& Connell, 2004). Although school is a major source of support and structure for youth, young people spend approximately $80 \%$ of their time outside of school (School's Out Washington, 2008). During early adolescence, young people spend a great deal of time in organized youth programs. It is estimated that over 8 million children and youth participate in after school programs annually, and over 14 million engage in such programming over the summer (Afterschool Alliance, 2009). As such, these programs have tremendous potential to provide meaningful support that can contribute to positive youth development. Further, involvement in positive, structured programs may decrease the potential for youth to engage in risky, negative behaviors (Mahoney, \& Stattin, 2000). 
Although it is hoped that young people benefit generally from youth programming, research has found that positive outcomes are only seen when such services are of high quality (Borden, Schlomer, \& Wiggs, 2011). The relationships between workers and youth can provide a pathway to positive youth development (Serido, Borden, \& Perkins, 2009). Thus, dedicating specific resources to ensuring excellence in youth programs is vital to youth outcomes. Specifically, improving the quality of youth programs has the potential to have positive ripple effects across a variety of life domains-academic achievement, social emotional and life skills development, health and well-being, and civic engagement can also be improved for young people (Borden \& Perkins, 2006; Hamilton, Hamilton, \& Pittman, 2004; Mahoney, Cairns \& Farmer, 2003; Walsh, 2007).

One of the key components of high quality youth programming is the presence of competent staff who understand the principles of positive youth development and create opportunities to promote such growth (Borden, et al., 2011). Although hiring staff with requisite training, experience, and interpersonal skills is important, ongoing monitoring, feedback, and mentoring are vital to improve skill sets. Staff who are systematically evaluated and routinely receive praise and supportive feedback on their work have the opportunity to grow and develop, thereby enhancing their competence as well as the potential benefits for the youth they serve. Evaluation of staff effectiveness is beneficial not only for individual competence and internal self-studies, but also can be helpful with site visits and accreditation reviews. Programs can use data from such evaluations to develop improvement plans, report achievements to funders and community stakeholders, and design additional quality programming.

\section{Overview of the Excel Initiative}

The Excellence in Youth Programming (Excel) Initiative (funded by the Departments of Defense's Office of Family Readiness Policy) strives to ensure programs that serve young people have the tools and resources needed to deliver high quality programs that promote the positive development of young people. Excel was specifically designed to increase the quality of out-ofschool-time programs. As part of this work, the Youth Development Observational Tool (YDOT) was developed to serve as the backbone of the Excel Initiative. YDOT allows for the virtual assessment of individuals (e.g. staff, youth development practitioners, program leaders) who work with youth ages 9-18 years. Unlike other program quality assessment tools that assess multiple environmental elements of a program, the focus of the YDOT is exclusively on the practitioner and his/her interactions with young people.

The YDOT observational tool is grounded in research focused on the eight key elements of high quality out-of-school programs:

(1) physical and psychological safety;

(2) supportive relationships;

(3) opportunities to belong;

(4) positive social norms;

(5) appropriate structure;

(6) support for efficacy and mattering;

(7) opportunities for skill building; and

(8) integration of family, school, and community efforts (Eccles, \& Gootman, 2002). 
Development of the YDOT was guided by the youth development literature (Borden, Scholmer, \& Wiggs, 2011) and items were designed to assess the key elements needed within after-school programs to promote the positive development of young people (Eccles, \& Gootman, 2002).

This assessment tool was created through a multi-stage process with the first stage requiring each survey item to be reviewed and vetted by researchers to ensure its consistency with the research literature. In the second stage, the tool was sent to national experts in the field of youth development for external review. During the third stage, the tool was used by a group of researchers and graduate students to determine inter-rater reliability through the watching and evaluating an after-school program. Reviewers were asked to view three 15-minute video segments of an after-school program and provide their ratings for each segment on rating forms. Reviewers were also asked to provide feedback regarding the usability of the tool. Each set of reviews was compiled and compared to the other reviews. Reviewers then met with the research group to discuss their experience and to clarify their ratings. Finally, the fourth stage involved the recruiting of individuals who had expertise in developing and conducting afterschool programs to use the observational tool in evaluating an after-school program. Scores were compiled and compared, and reviewers then met and discussed their responses. The research team used the information from each stage to make changes to the observational tool to ensure a reliable tool.

Procedurally, the Excel Initiative begins with youth programs identifying three staff members who upload three separate 10-minute videos to the secure online platform developed for Excel. In order to capture a full range of staff youth programming skills and activities, each of the 10minute videos is required to come from different program offerings, as well as from three distinct staff members. Each video is carefully reviewed and scored by an Excel master coach. In scoring the videos, coaches use eight distinct components within each of the eight Eccles and Gootman (2002) key elements, scoring a total of 64 components. Master coaches also take observational notes and record feedback during this time. The coach then provides virtual (e.g., telephone, vide conference) feedback and guidance to each individual who provided the videos, with a summary report about the overall program provided to the program administrator.

In this way, the Excel Initiative scores and provides feedback for the overall program, rather than for individual staff members. This program is designed to improve program quality and thus is not designed as a way to evaluate employees. The coach also works directly with the program director to implement a program improvement plan. During this time, professional development modules (from the Military Research and Outreach website) are offered in areas of needed growth, and coaches can develop goals and objectives for program improvement.

\section{Unique Features of the Excel Initiative}

Numerous observational and coaching tools for youth programs exist (for a review, see Brosi, 2011). Examples of commonly used tools include the Youth Program Quality Assessment Tool (YPQA) (Smith, \& Hohmann, 2005), the National Collaboration for Youth's Competency Observation Assessment Tool (Astroth, Batchelor, Garza, Scanlin, \& Taylor, nd), and the Out-ofSchool Time (OST) Observation Instrument (Russell, 2008). Most such observation tools are designed to assess overall program operations and function. In contrast, the Excel Initiative uses the YDOT, which is specifically designed to assess the relationships between adults and young people who participate in after-school programs. Feedback is provided at the program level rather than the individual level, addressing skill areas of strength and areas of 
development that are based on research-supported features of youth programs (e.g., Eccles, \& Gootman, 2002).

Another unique feature of the YDOT tool pertains to it being available online to programs across the world. Users interact with the program through a secure online platform, providing numerous advantages. This virtual platform:

- Eliminates the need for face-to-face contact

- Eliminates the time and cost of coach/evaluator travel

- Affords significant cost savings to programs looking for coaching

- Provides easy, convenient access to all programs in both urban and in remote areas

- Allows for unobtrusive assessment of worker-youth interactions because program participants are not faced with an unknown observer

Importantly, the YDOT assessment tool is integrated into a broader network of resources. The online platform includes an on-line interactive course for each topic addressed in the assessment; thus, child care professionals who wish to enhance their skills in a certain domain can easily access focused training to increase their effectiveness.

\section{Conclusions and Future Directions}

In conclusion, the Excel Initiative offers much to out-of-school time programs through the use of the YDOT, master coaching, and associated tools and resources. Programs wishing to participate in Excel may consider using professional development dollars to fund this initiative, or they may partner with local community foundations to fund staff development of this nature. This initiative is a promising, innovative approach to observing and mentoring those that work with and on behalf of young people. Through the funding effort of this project, the Department of Defense is demonstrating creativity and initiative in pioneering a novel approach that can be used across a spectrum of youth development programs. The Excel Initiative is a promising new program that provides development and growth opportunities to youth development staff throughout the world through the use of the YDOT, coaching, innovative tools, and researchbased resources.

\section{References}

Afterschool Alliance. (2009). American After 3pm: The most in-depth study of how America's children spend their afternoons. Retrieved from

http://www.afterschoolalliance.org/AA3 Full Report.pdf

Astroth, K., Batchelor, R., Garza, P., Scanlin, M., \& Taylor, B. (nd). National Youth Development Network's Competency Observation Assessment Tool. Retrieved from http://www.renewaloutfitters.org/Navigators/Competency-Assessment-Tool.pdf

Borden, L.M., \& Perkins, D.F. (2006). Community youth development professionals: Providing the necessary supports. Child and Youth Care Forum, 35(2), 101-158

Borden, L.M., Schlomer, G.L., \& Wiggs, C.B. (2011). The evolving role of youth workers. Journal of Youth Development, 6(3), 127-138. 
Brosi, E. (2011). Measurement Tools for Evaluating Out-of-School Time Programs: An Evaluation Resource. Harvard Family Research Project Research Report. Retrieved from: http://www.hfrp.org/out-of-school-time/publications-resources/measurement-tools-for evaluating-out-of-school-time-programs-an-evaluation-resource2\#table2-7

Eccles, J., \& Gootman, J.A. (2002). Community programs to promote youth development. National Academies Press.

Gambone, M.A., \& Connell, J.P. (2004). Toward a community action framework for youth development. The Prevention Researcher, 11, 17-20.

Hamilton, S.F., Hamilton, M.A., \& Pittman, K. (2004). Principles for youth development. In S.F. Hamilton \& M.A. Hamilton (Eds.), The youth development handbook: Coming of age in American communities (pp.3-22). Thousand Oaks: Sage Publications.

Mahoney, J.L., Cairns, B.D. \& Farmer, T.W. (2003). Promoting interpersonal competence and educational success through extracurricular activity participation. Journal of Educational Psychology, 95(2), 409-418. doi: 10.1037/0022-0663.95.2.409

Mahoney, J.L., \& Stattin, H. (2000). Leisure activities and adolescent antisocial behavior: The role of structure and social context. Journal of Adolescence, 23(2), 113-127.

Russell, C.A. (2008). Out-of-School Time (OST) Observation Instrument. C.S. Mott Foundation. Retrieved from http://www.policystudies.com/studies/?id=30

School's Out Washington. (2008). A Well-Prepared Workforce Brings Out the Best in Our Kids A Framework for a Professional Development System for the Afterschool and Youth Development Workforce of Washington State. Retrieved from:

http://www.schoolsoutwashington.org/documents/workforce\%20study\%20full\%20report.pdf

Serido, J., Borden, L.M., \& Perkins, D. (2009). Moving beyond youth voice. Youth \& Society, 43, 44-63.

Smith, C., \& Hohmann, C. (2005). Full findings from the Youth PQA validation study. Ypsilanti, MI: High Scope Educational Research Foundation.

Walsh, D. (2007). Supporting youth development outcomes: An evaluation of a responsibility model-based program. The Physical Educator, 64, 48-56.

(c) Copyright of Journal of Youth Development $~$ Bridging Research and Practice. Content may not be copied or emailed to multiple sites or posted to a listserv without copyright holder's express written permission. Contact Editor at: patricia.dawson@oregonstate.edu for details. However, users may print, download or email articles for individual use.

ISSN 2325-4009 (Print); ISSN 2325-4017 (Online) 